University of Montana

ScholarWorks at University of Montana

$10-2006$

\title{
Gene Flow in Complex Landscapes: Testing Multiple Hypotheses with Causal Modeling.
}

Samuel A. Cushman

Kevin Scot McKelvey

The University of Montana

Jim Hayden

Michael K. Schwartz

University of Montana - Missoula, mkschwartz@fs.fed.us

Follow this and additional works at: https://scholarworks.umt.edu/wildbio_pubs

Part of the Life Sciences Commons

Let us know how access to this document benefits you.

\section{Recommended Citation}

Cushman, Samuel A.; McKelvey, Kevin Scot; Hayden, Jim; and Schwartz, Michael K., "Gene Flow in Complex Landscapes: Testing Multiple Hypotheses with Causal Modeling." (2006). Wildlife Biology Faculty Publications. 73.

https://scholarworks.umt.edu/wildbio_pubs/73

This Article is brought to you for free and open access by the Wildlife Biology at ScholarWorks at University of Montana. It has been accepted for inclusion in Wildlife Biology Faculty Publications by an authorized administrator of ScholarWorks at University of Montana. For more information, please contact scholarworks@mso.umt.edu. 


\section{CHICAGO JOURNALS}

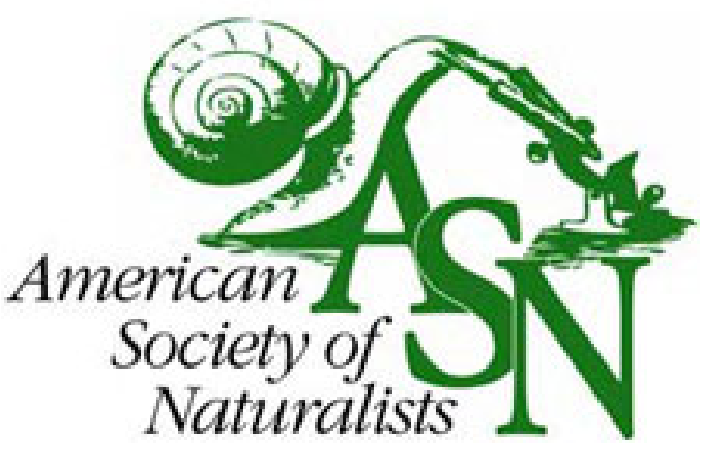

The University of Chicago

Gene Flow in Complex Landscapes: Testing Multiple Hypotheses with Causal Modeling. Author(s): Samuel A. Cushman, Kevin S. McKelvey, Jim Hayden, and Michael K. Schwartz Source: The American Naturalist, Vol. 168, No. 4 (October 2006), pp. 486-499

Published by: The University of Chicago Press for The American Society of Naturalists

Stable URL: http://www.jstor.org/stable/10.1086/506976

Accessed: 06/05/2014 16:04

Your use of the JSTOR archive indicates your acceptance of the Terms \& Conditions of Use, available at http://www.jstor.org/page/info/about/policies/terms.jsp

JSTOR is a not-for-profit service that helps scholars, researchers, and students discover, use, and build upon a wide range of content in a trusted digital archive. We use information technology and tools to increase productivity and facilitate new forms of scholarship. For more information about JSTOR, please contact support@jstor.org. 


\title{
Gene Flow in Complex Landscapes: Testing Multiple Hypotheses with Causal Modeling
}

\author{
Samuel A. Cushman, ${ }^{1, *}$ Kevin S. McKelvey, ${ }^{1, \uparrow}$ Jim Hayden, ${ }^{2, *}$ and Michael K. Schwartz ${ }^{1, \varsigma}$
}

1. U.S. Department of Agriculture/U.S. Forest Service Rocky Mountain Research Station, Missoula, Montana 59807;

2. Idaho Department of Fish and Game, Coeur d'Alene, Idaho 83815

Submitted January 12, 2006; Accepted June 9, 2006;

Electronically published August 7, 2006

AвSTRACT: Predicting population-level effects of landscape change depends on identifying factors that influence population connectivity in complex landscapes. However, most putative movement corridors and barriers have not been based on empirical data. In this study, we identify factors that influence connectivity by comparing patterns of genetic similarity among 146 black bears (Ursus americanus), sampled across a $3,000-\mathrm{km}^{2}$ study area in northern Idaho, with 110 landscape-resistance hypotheses. Genetic similarities were based on the pairwise percentage dissimilarity among all individuals based on nine microsatellite loci (average expected heterozygosity $=0.79$ ). Landscape-resistance hypotheses describe a range of potential relationships between movement cost and land cover, slope, elevation, roads, Euclidean distance, and a putative movement barrier. These hypotheses were divided into seven organizational models in which the influences of barriers, distance, and landscape features were statistically separated using partial Mantel tests. Only one of the competing organizational models was fully supported: patterns of genetic structure are primarily related to landscape gradients of land cover and elevation. The alternative landscape models, isolation by barriers and isolation by distance, are not supported. In this black bear population, gene flow is facilitated by contiguous forest cover at middle elevations.

Keywords: connectivity, landscape resistance, least-cost paths, microsatellite, population genetics, Ursus americanus.

Habitat fragmentation has been shown to decrease dispersal (Gibbs 1998; deMaynadier and Hunter 2000), in-

\footnotetext{
* Corresponding author; e-mail: scushman@fs.fed.us.

† E-mail: kmckelvey@fs.fed.us.

‡ E-mail: jhayden@idfg.idaho.gov.

s E-mail: mkschwartz@fs.fed.us.
}

Am. Nat. 2006. Vol. 168, pp. 486-499. (C) 2006 by The University of Chicago. 0003-0147/2006/16804-41553\$15.00. All rights reserved. crease mortality (Fahrig et al. 1995; Carr and Fahrig 2001), and reduce genetic diversity (Saccheri et al. 2001; Frankham et al. 2002; Vilà et al. 2002), thereby increasing extinction risk (Lande 1988; Tallmon et al. 2004). Despite the clear importance of habitat connectivity for population persistence, specific factors mediating connectivity are largely unknown for most species (With et al. 1997; Bowne and Bowers 2004; Cushman 2006). Landscapes are perceived by particular species in ways that may not correspond to our assumptions concerning connectivity and habitat quality (With et al. 1997; Wiens 2001). Many studies have represented the landscape as a binary mosaic of suitable and unsuitable habitat (e.g., Danielson and Hubbard 2000; Coulon et al. 2004); however, it is more likely that organisms experience landscapes as gradients of varying quality and resistance to movement rather than as mosaics of uniformly good habitat in a uniformly inhospitable matrix (McIntyre and Barrett 1992; Manning et al. 2004; McGarigal and Cushman 2005).

Traditional approaches for measuring species-specific dispersal are logistically complicated. Even the largest studies using the latest Global Positioning System collars can track only relatively few individuals over time (e.g., $<30$; Gaines et al. 2005). Measuring dispersal using these methods is further complicated by confounding dispersal events with exploratory movements, where an animal moves a large distance only to return to its original territory without breeding. Alternatively, genetic approaches can be used to estimate dispersal and immigration (Waples 1998; Schwartz et al. 2002). Logistical and financial costs associated with tracking individual animals are obviated and, because genetic data integrate time, slow rates of dispersal are measurable. Furthermore, genetic metrics integrate only those movements that produce meaningful population effects-dispersals that result in breeding or emigration.

Most population genetic studies have used models that consider populations to be mutually isolated and internally panmictic. The most common approaches involve $F$ statistics or assignment tests to assess genetic differences among well-defined subpopulations (Wright 1943; Mills 
and Allendorf 1996; Wasser and Strobeck 1998). Recently, models such as STRUCTURE (Pritchard et al. 2000; Evanno et al. 2005) that cluster individuals by minimizing Hardy-Weinberg and gametic disequilibrium have been used to define the subpopulations. Once discrete subpopulations have been identified, post hoc analyses are performed, correlating observed genetic patterns with interpopulation distance or putative movement barriers (e.g., Proctor et al. 2005). Populations, however, often have substantial internal structure (Wright 1943; Gompper et al. 1998; Van Horn et al. 2004), and, except in special cases like oceanic islands or mountain lakes, it is often difficult to rigorously define discrete boundaries between populations. In terrestrial landscapes, it is more common to have species that are either continuously distributed or patchily distributed with low densities between populations (Manel et al. 2003). Thus, in many situations, population structure is better defined as a gradient phenomenon than as a categorical, patch-based entity. In recognition of this, researchers have recently begun to adopt "landscape genetic" approaches, where individuals are sampled across broad landscapes, genetic relatedness between individuals assessed, and these relationships correlated with landscape features (Vitalis and Couvet 2001; Manel et al. 2003; Coulon et al. 2004, 2006; Scribner et al. 2005).

Patterns of genetic relatedness among individuals can be correlated with landscape features by building resistance surfaces that assign different resistance-to-movement values to different landscape features. A matrix of movement costs can then be computed, based on the least-cost paths between all pairs of individuals. By comparing genetic differentiation among individuals with cost distances between them, researchers can test specific hypotheses about the influences of landscape features and environmental conditions on gene flow (Vos et al. 2001; Coulon et al. 2004, 2006; Spear et al. 2005).

This study extends existing landscape genetic methods (Manel et al. 2003) by using a factorial, multimodel approach to evaluate alternative hypotheses and identify the combination of environmental factors that appear to drive gene flow in this landscape. We used noninvasive genetic sampling (Taberlet et al. 1997; Kohn et al. 1999), leastcost path modeling, and partial Mantel tests to test 110 hypotheses describing alternative relationships between landscape factors and gene flow in an American black bear (Ursus americanus) population in Idaho. These hypotheses were organized into seven organizational models incorporating all combinations of barriers, distance, and landscape-resistance gradients. Our primary goal was to determine the relative influences of genetic isolation by putative movement barriers, geographical distance, roads, land cover, and topographical slope as well as to identify the combination of factors with the greatest support as a causal model explaining gene flow among black bears in the study area.

\section{Methods \\ Study Area}

The study area consists of an approximately $3,000-\mathrm{km}^{2}$ area of the Idaho Panhandle National Forest, located in the extreme northern tip of Idaho (fig. 1) and comprising parts of the Selkirk and Purcell mountain ranges. The topography is mountainous, with steep ridges, narrow valleys, and many cliffs and cirques at the highest elevations. Elevation ranges from approximately 700 to $2,400 \mathrm{~m}$. The Kootenai River trench bisects the study area, separating the Selkirk Mountains on the west from the Purcell Mountains on the east with a 5-8-km-wide unforested, agricultural valley and a broad, deep river. This valley is the putative barrier used in our barrier model, discussed below. The climate is characterized by cold, wet winters and mild summers. The area is heavily forested, with Abies lasiocarpa (subalpine fir) and Picea engelmannii (Engelmann spruce) codominant above $1,300 \mathrm{~m}$ and a diverse mixed conifer forest dominating below $1,300 \mathrm{~m}$.

\section{Genetic Sampling}

Genetic samples were obtained using noninvasive hair snaring during June, July, and August 2003. Hair snaring followed the protocols of Proctor et al. (2005). Each sampling station was checked at approximately 14-day intervals. All hair on each barb was considered a single sample for lab work (Woods et al. 1999; Mowat and Strobeck 2000). The corrals were set at 266 National Vegetation Pilot plots (Morgan et al. 2004; fig. 1). The National Vegetation Pilot project established a grid of permanent vegetation plots at $1.6-\mathrm{km}$ spacing across the study area to allow monitoring of vegetation change.

\section{Genetic Analysis}

We subsampled by randomly selecting one sample from each series of adjacent samples in a corral unless the series of adjacent samples was more than five, in which case the first and last samples were used. We detected no deviations from Hardy-Weinberg proportions, found no evidence of gametic disequilibrium, and calculated a probability of identity (Evett and Weir 1998) of $1.82 \times 10^{-11}$ and a probability of identity assuming siblings (Evett and Weir 1998) of $1.26 \times 10^{-4}$ for a nine-locus genotype, allowing ample power to discern individuals. Expected heterozygosity in the Purcell mountain range was 0.78 and in the Selkirk 


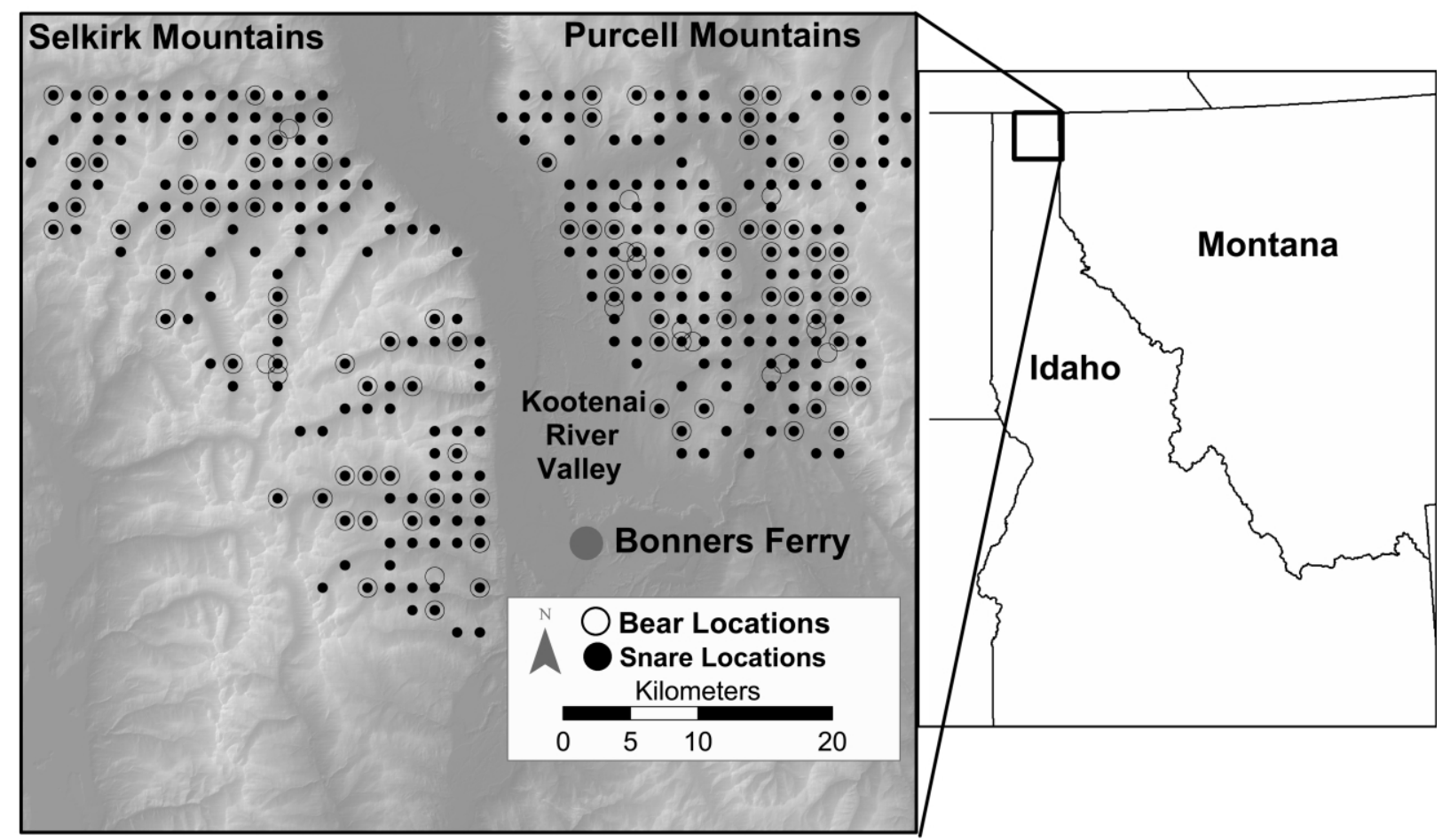

Figure 1: Study area orientation map. The geographical coordinates for each hair snare are shown as black dots and the locations for each bear as circles. When a bear was sampled at more than one snare, we used the centroid of its multiple captures as its location for analysis.

mountain range was 0.80 , while observed heterozygosity was 0.76 and 0.80 for each range, respectively (Schwartz et al. 2006).

\section{Genetic Distance}

Each bear was assumed to represent the population of bears at the location where it was sampled. We coded each individual's alleles from a nine-locus genotype as 0 (allele absent), 1 (allele found as one of two alleles; a heterozygote), or 2 (a homozygous individual with two copies of the allele). This produced a matrix with 90 columns, one for each allele in the pool of sampled bears, and 146 rows representing individual bears. We used the Bray-Curtis percentage dissimilarity measure of genetic distance among individuals (Legendre and Legendre 1998), producing a matrix containing the genetic distances among all pairs of sampled bears. This calculation assumes that the loci are independent, consistent with linkage disequilibrium results. The $a_{\mathrm{r}}$ metric (Rousset 2000) has been suggested as a measure of genetic dissimilarity among individuals. However, we feel percentage dissimilarity is preferable because it accounts for the semiquantitative nature of the three-state genetic data and also discounts double negatives. The Pearson correlation coefficient between our genetic measure and the $a_{\mathrm{r}}$ measure was more than 0.97 , indicating that for this data set, the two metrics are nearly identical and would yield similar conclusions.

\section{Organizational Models}

A priori, we identified three potential drivers of genetic structure in this black bear population, including isolation by the Kootenai River valley as a barrier, isolation by geographic distance, and isolation by landscape-resistance gradients. There are seven possible patterns of causality among the barrier, distance, and landscape-resistance gradients and the genetic structure of this black bear population (fig. 2). Our goal was to determine the relative support for isolation by distance and barriers in comparison to isolation by gradients of landscape resistance. We used causal modeling on resemblance matrices (Legendre and Troussellier 1988; Legendre 1993) to identify which of the seven models had the strongest support. Each organizational model has a diagnostic set of statistical tests to evaluate its support. By comparing statistical relationships between genetic structure and each hypothesis with those expected under each organizational model, we determined which of the seven organizational models was fully supported. 


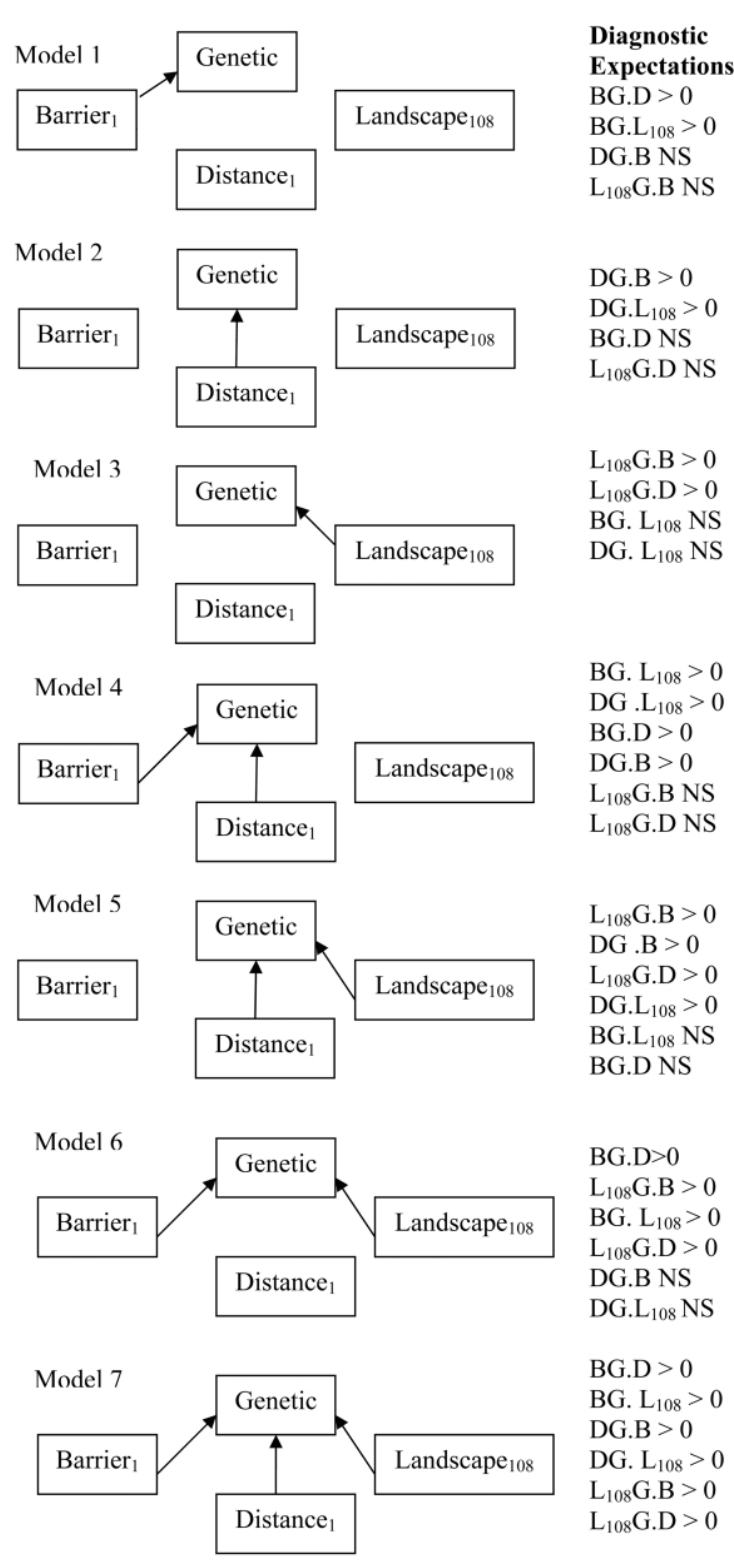

Figure 2: Description of the seven organizational models tested. Model 1 is isolation by barriers; model 2, isolation by distance; model 3, isolation by landscape-resistance gradients; model 4 , isolation by a combination of barriers and distance; model 5 , isolation by distance and landscaperesistance gradients; model 6 , isolation by barriers and landscaperesistance gradients; and model 7 , isolation by a combination of barriers, distance, and landscape-resistance gradients. Diagnostic expectations are a list of the partial Mantel tests used to evaluate each model and the expected patterns of significance if the model is correct: $G=$ genetic distance; $B=$ barrier; $D=$ distance; $L_{108}=$ landscape. A period separates the main matrices on the left from the covariate matrix on the right that is partialed out in the partial Mantel tests. For example, BG.D is a partial Mantel test between the barrier and genetic-distance matrices, with the geographicdistance matrix partialed out. The landscape factor has a subscript of 108 , indicating that there are 108 landscape cost-distance matrices representing the factorial combination of the factors elevation, slope, roads, and land cover.

\section{Landscape-Resistance Gradients}

Isolation by distance and isolation by barriers are the hypotheses most commonly tested in the literature (Wright 1943; Forbes and Hogg 1999; Schwartz et al. 2002). Isolation by a barrier was represented as a single hypothesis, wherein we predicted panmixia on either side of the Kootenai River valley, with no gene flow between. Isolation by distance was also represented as a single hypothesis, with genetic similarity predicted to decrease linearly with Euclidian distance.

In addition to the models of isolation by a barrier and isolation by distance, we produced 108 landscaperesistance surfaces representing the factorial combinations of four landscape factors: elevation, slope, roads, and land cover (table 1). Resistance of these factors to gene flow was modeled across four levels for elevation and three levels for the other factors, producing 108 hypotheses. The resistance maps corresponding to each factor were combined into the 108 landscape-resistance models by addition. After addition, the minimum value on the combined grids was 4 , reflecting the sum of the minimum values of the four factors. These hypotheses were represented by Geographic Information System raster maps whose cell values were equal to the hypothetical resistance of each cell to gene flow. Before analysis, the base maps were resampled to $90-\mathrm{m}$ pixel size and rectified to a Universal Transverse Mercator projection (table 2).

There were four motivations for this selection of landscape-resistance hypotheses. First, unlike in the cases of isolation by barrier or isolation by distance, there are many factors that can potentially influence gene flow when it is modeled as a function of landscape structure. A priori, it is questionable to assume which landscape features are most strongly related to gene flow and in what ways. Thus, a multifactor approach is necessary. Second, the four factors of elevation, slope, roads, and land cover are the landscape features to which black bears respond most strongly (Brody and Pelton 1989; Lyons et al. 2003). Slope and elevation are the most informative measures of physiography; roads and land cover have well-established relationships to habitat quality and movement for a wide range of organisms (Bowne and Bowers 2004; Cushman 2006) and for black bears in particular (Michell and Powell 2003; Gaines et al. 2005). Third, we specified a range of levels for each factor, allowing the relative importance of each factor to be expressed in a multifactor model. In this approach, models are most sensitive to the relative magnitude of the factors, not their specific values. Thus, the levels were chosen to cover the range of each factor on the landscape, and all factors were scaled between 1 and 10, allowing each factor to speak with equal weight. Finally, we 
Table 1: Description of factors and levels combined to create 108 landscape-resistance hypotheses

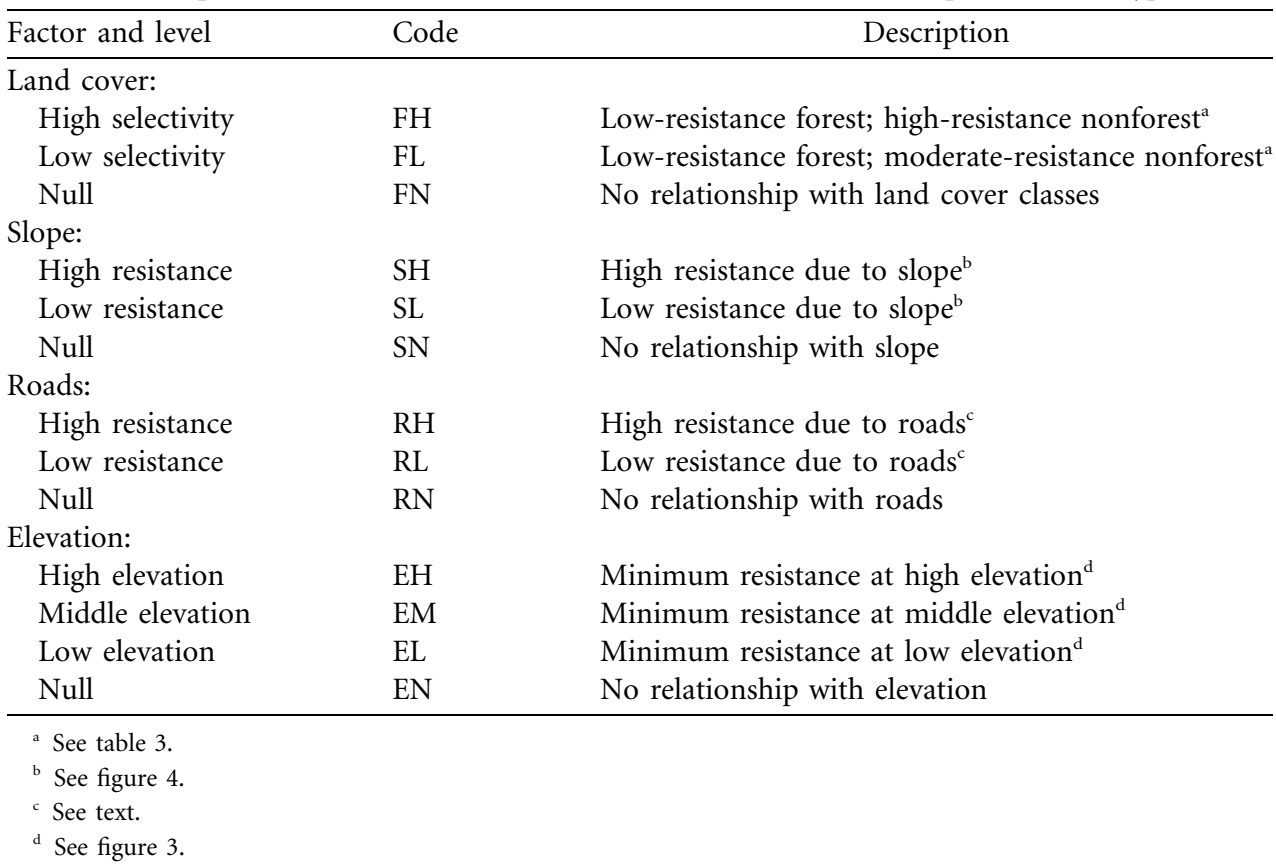

produced models representing all combinations of these factors.

Landscape resistance due to elevation was modeled at four levels, including a null model. Resistance was modeled as an inverted Gaussian function and was parameterized with a minimum of 1 and a maximum approaching an asymptote of 10 . The standard deviation of the curve was $1,000 \mathrm{~m}$. The levels differed only in the elevation at which the function reached its minimum value. The three levels of elevation had resistance minima at 500, 1,000, and 1,500 $\mathrm{m}$, respectively (fig. 3). These three levels reflect a range of potential relationships between resistance to movement and elevation, with increasing resistance to gene flow at elevations higher and lower than the minima, with a maximum resistance of 10 times that of the minima achieved at the asymptote. The null model predicted resistance of 1 at all elevations.

Landscape resistance due to slope was modeled as a linear function and included three levels. The linear func- tions had $y$-intercepts at 1 and differed only in slope. Topographical slope was measured in percent. The linear functions were parameterized such that the low and high slope effect models produced resistances of two and five times, respectively, that of the $y$-intercept at a slope of $100 \%$ (fig. 4). The null model predicted a resistance of 1 at all slopes.

Landscape resistance due to roads and land cover were both represented as categorical functions. The study area contains a range of road types and traffic volumes. However, no data on traffic volume were available, so this analysis considered only road type. Roads were classified as "major highway" and "other road," which included county and U.S. Forest Service gated and ungated roads. High and low road effect levels assigned resistance values of 5 and 10 to "major highway" and 2 and 5 to "other road," respectively. All nonroad pixels were given a value of 1 . The null model predicted a road resistance of 1 for all pixels.

We tested three levels of resistance due to land cover,

Table 2: Metadata for all coverages used in the analysis

\begin{tabular}{lll}
\hline Coverage & \multicolumn{1}{c}{ Description } & \multicolumn{1}{c}{ Source } \\
\hline Land cover & Categorical map of land cover classes & Gap analysis program \\
Roads & Raster map of roads, including two classes: major highways and other roads & TIGER 1997 \\
Slope & Slope in percent & Derived from 30-m DEM \\
Elevation & Elevation in meters & Derived from 30-m DEM \\
\hline
\end{tabular}

Note: All coverages were resampled to raster grids with 90-m cell size and coregistered in a Universal Transverse Mercator projection. $\mathrm{DEM}=$ digital elevation model.

${ }^{a}$ See table 3 for list of classes and resistance values assigned.

${ }^{\mathrm{b}} \mathrm{http}: / /$ www.census.gov/geo/www/tiger/. 


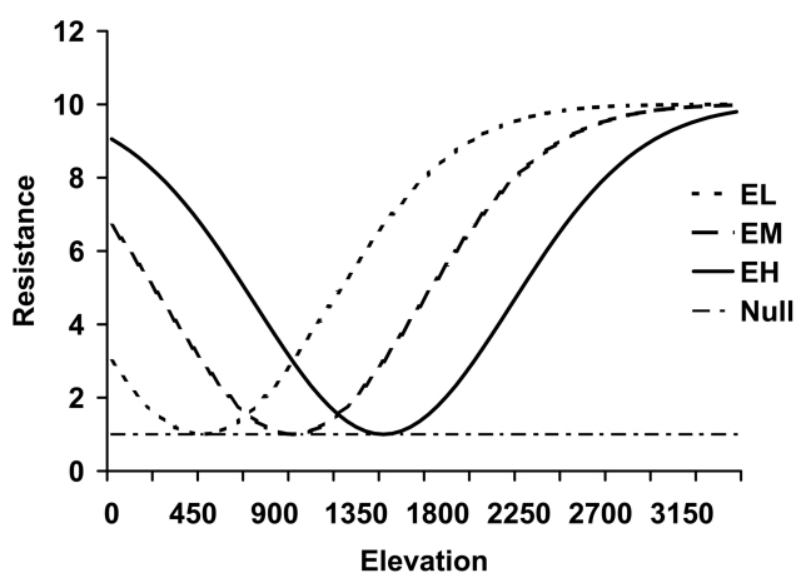

Figure 3: Functions used to develop hypotheses regarding resistance due to elevation. The four levels include three Gaussian functions of resistance with respect to elevation and one null model. The three Gaussian levels each have a standard deviation of $1,000 \mathrm{~m}$, a minimum of 1 , and a maximum of 10 . They differ only in the elevation at which the minimum resistance is achieved: $500 \mathrm{~m}$ for $E L, 1,000 \mathrm{~m}$ for $E M$, and 1,500 $\mathrm{m}$ for $E H$ (see table 1 for abbreviations). The null model predicts a resistance of 1 for all elevations.

including a null model. The land cover classification used in this analysis included 26 categories representing different land cover types (table 3 ). The first level reflected a strong relationship between gene flow and forest cover, with strong resistance to movement across nonforest classes, such as urban and agricultural areas. The second level reflected a less obligate relationship with forest cover, and the third level was the null model, which predicted no relationship between land cover and gene flow (table 3).

\section{Cost Models}

Cost distances are the cumulative costs associated with traversing the least-cost route from each individual bear's location to every other bear's location. When an individual bear was found at more than one sample location, the centroid of the locations was used. We used the ArcGIS COSTDISTANCE function (ESRI 2003) to create cost matrices reflecting the least-cost distance from the location at which each bear's DNA sample was recorded to every other bear's location across each of the 108 resistance surfaces.

The isolation-by-distance hypothesis yielded a cost matrix that contained the Euclidean distances based on UTM coordinates between all pairs of bears. The barrier model was represented as a categorical model matrix (Legendre and Legendre 1998) that predicted panmixia within both the Selkirk and Purcell mountain ranges, with the Kootenai River valley a perfect barrier between (fig. 1).

\section{Mantel Tests}

We used Mantel (Mantel 1967) and partial Mantel (Smouse et al. 1986) tests within a causal modeling framework (Legendre 1993) to assess the support for seven organizational models containing the 110 resistance hypotheses (fig. 2). Causal modeling on resemblance matrices uses simple and partial Mantel correlation coefficients to evaluate the degree of support for alternative hypotheses of causality (Legendre and Troussellier 1988). The Mantel test measures the degree of association between two dissimilarity matrices. In this case, these matrices correspond to the hypothetical least-cost distances (independent-variable set) and the genetic differences among bears (dependentvariable set). Significant Mantel correlation between the genetic matrix and a cost matrix would indicate that the genetic structure of the population is correlated with a specific landscape-resistance hypothesis. In multivariate correlational modeling, the apparent strength of explanation increases with increasing numbers of parameters, even if the added variables have no actual relationship with the response variable. In our approach, we tested a single response variable (genetic distance) against single predictor variables (each landscape-resistance hypothesis). Because all of the factors associated with a landscaperesistance hypothesis were combined to produce a single resistance hypothesis, there is no inflation of explained variance due to number of factors associated with a resistance hypothesis. We therefore ranked Bonferronicorrected $P$ values to evaluate support. All Mantel tests were conducted using R-Package software (Legendre and Vaudor 1991).

We used a two-step procedure to evaluate these models. First, we computed the Mantel correlation and Monte

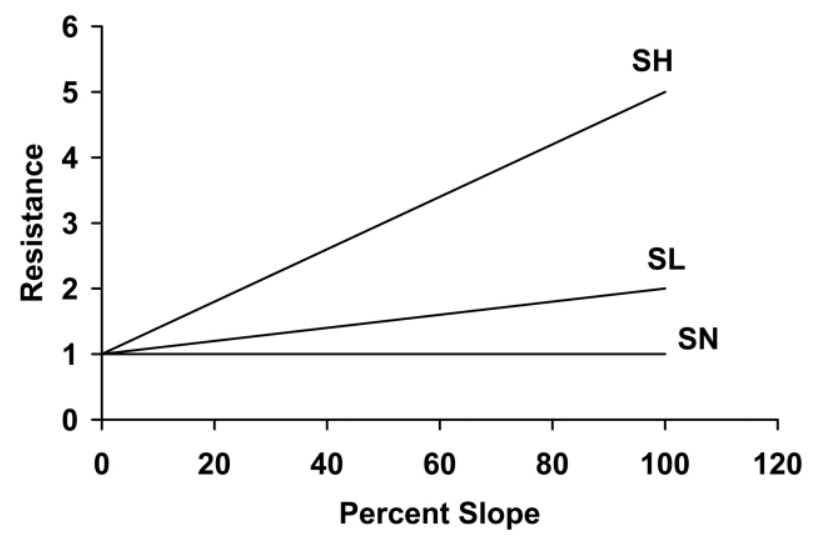

Figure 4: Linear functions used to develop hypotheses regarding resistance due to slope. $S H$ is high resistance, $S L$ is low resistance, and $S N$ is the null model, predicting that slope has no effect on gene flow. 
Table 3: Cover classes and resistance values used in land cover-resistance modeling

\begin{tabular}{lcc}
\hline Cover class & $\begin{array}{c}\text { Resistance } \\
\text { in FL }\end{array}$ & $\begin{array}{c}\text { Resistance } \\
\text { in FH }\end{array}$ \\
\hline Urban, water & 10 & 10 \\
Water & 10 & 10 \\
Surface mining & 7 & 10 \\
Shrub flats & 7 & 8 \\
Rock & 6 & 6 \\
Agricultural, snowfields, or ice & 5 & 7 \\
Snowfields or ice & 5 & 6 \\
Mixed barren lands & 4 & 6 \\
Alpine meadow, shrub- & & \\
$\quad$ dominated riparian, grass- & & \\
$\quad$ dominated riparian, wet- & & \\
lands, mesic upland shrub, & & \\
$\quad$ xeric upland shrub, sub- \\
$\quad$ alpine meadow \\
Clear-cut conifer, burned forest
\end{tabular}

Note: FL $=$ low-selectivity land cover model; FH $=$ high-selectivity land cover model (table 1).

Carlo $P$ value for each simple and partial Mantel correlation between the genetic-distance matrix and the matrices corresponding to the barrier, distance, and landscape hypotheses. This involved computing simple and partial Mantel correlation coefficients for each organizational model (fig. 2). Second, we compared the observed pattern of correlation coefficients and $P$ values with the expectations of the seven organizational models. We eliminated organizational models that were inconsistent with the pattern of support among resistance hypotheses and identified the organizational model with the greatest support.

\section{Results}

A total of 663 samples were collected from 169 of the 266 hair snare stations. We ran microsatellite analyses on 245 samples, from which 146 unique bears were identified ( 97 samples were recaptures, and 2 samples were discarded due to multiple individuals leaving samples at a barb or poor quality of samples; fig. 1). Approximately $87 \%$ of all bears were detected at only one snare. Eighteen bears were captured at two snares, one at three, and no bears were detected at more than three stations. The average and maximum distances between detections were 3.4 and $7.5 \mathrm{~km}$, respectively. Of the bears captured at multiple locations, no individuals were captured on both sides of the Kootenai River valley or in areas separated by major ridges.

\section{Significance and Rankings of the 110 Models}

All 110 resistance hypotheses were significantly related to the pattern of genetic difference among bears after Bonferroni correcting for experiment-wise error rates (corrected $P<.05$ in all cases). The barrier hypothesis was ranked 102 out of 110 in terms of the magnitude of the Mantel correlation coefficient. The isolation-by-distance hypothesis was more strongly supported and was ranked 35 out of the 110 total models.

\section{Support for Organizational Models}

Only one of the seven hypothetical organizational models was fully supported by all statistical expectations (table 4). This model, model 3 , predicts that gene flow in this population is influenced predominantly by landscape-resistance gradients with no significant independent relationships with the Kootenai River barrier or geographical distance (fig. 2).

Sixty-six of the 108 landscape-resistance hypotheses were significantly $(P<.05)$ related to genetic patterns among bears after the effects of the barrier hypothesis were removed. Ten of the landscape-resistance hypotheses were significantly related $(P<.05)$ to the genetic patterns after the effects of distance were removed with partial Mantel tests (table 5).

After the effects of distance are partialed out, ranking the 10 significant partial models by the Monte Carlo $P$ value provides a means to determine which hypotheses have the greatest support and to identify the combination of landscape factors most related to the genetic structure of this population (fig. 5). The 10 significant partial models were all concentrated in one small area of a four-dimensional factorial space (roads, elevation, forest cover, slope), indicating a unimodal peak of support. Within this small area of concentration, the best-supported models were associated with minimum resistance to movement at middle elevations, high resistance of nonforested habitat to movement, no relationship with slope, and equivocal support for the different levels of road resistance (fig. 5). A map extrapolating the understanding from the most highly supported model across the entire study area is shown in figure 6 .

\section{Discussion}

Causal modeling (Legendre and Troussellier 1988) of relationships between genetic dissimilarity among individuals and multiple alternative hypotheses of landscape resistance provides a means to rigorously evaluate the factors that limit gene flow. By testing seven organizational mod- 
Table 4: Evaluation of seven organizational hypotheses

\begin{tabular}{|c|c|}
\hline Model and expectation & Monte Carlo $P$ value \\
\hline \multicolumn{2}{|c|}{ Model 1, isolation by barrier: } \\
\hline BG.D $>0$ & .065 \\
\hline BG.L $>0$ & 108 of $108>.05$ \\
\hline DG.B NS & .035 \\
\hline LG.B NS & 66 of $108<.05$ \\
\hline \multicolumn{2}{|c|}{ Model 2, isolation by distance: } \\
\hline DG.B $>0$ & .035 \\
\hline DG.L $>0$ & 108 of $108>.05$ \\
\hline BG.D NS & .065 \\
\hline LG.D NS & 10 of $108<.05$ \\
\hline \multicolumn{2}{|c|}{ Model 3, isolation by landscape resistance: } \\
\hline LG.B $>0$ & 66 of $108<.05$ \\
\hline LG.D $>0$ & 10 of $108<.05$ \\
\hline BG.L NS & 108 of $108>.05$ \\
\hline DG.L NS & 108 of $108>.05$ \\
\hline \multicolumn{2}{|c|}{ Model 4 , isolation by barrier and distance: } \\
\hline BG.L $>0$ & 108 of $108>.05$ \\
\hline DG.L $>0$ & 108 of $108>.05$ \\
\hline BG.D $>0$ & .065 \\
\hline DG.B $>0$ & .035 \\
\hline LG.B NS & 66 of $108<.05$ \\
\hline LG.D NS & 10 of $108<.05$ \\
\hline \multicolumn{2}{|c|}{ Model 5, isolation by distance and landscape: } \\
\hline LG.B $>0$ & 66 of $108<.05$ \\
\hline DG.B $>0$ & .035 \\
\hline LG.D $>0$ & 10 of $108<.05$ \\
\hline DG.L $>0$ & 108 of $108>.05$ \\
\hline BG.L NS & 108 of $108>.05$ \\
\hline BG.D NS & .065 \\
\hline \multicolumn{2}{|c|}{ Model 6, isolation by barrier and landscape: } \\
\hline BG.D $>0$ & .065 \\
\hline LG.B $>0$ & 66 of $108<.05$ \\
\hline LG.D $>0$ & 10 of $108<.05$ \\
\hline DG.B NS & .035 \\
\hline DG.L NS & 108 of $108<.05$ \\
\hline \multicolumn{2}{|c|}{ Model 7, isolation by barrier, distance, and landscape: } \\
\hline BG.D $>0$ & .065 \\
\hline BG.L $>0$ & 108 of $108<.05$ \\
\hline DG.B $>0$ & .035 \\
\hline DG.L $>0$ & 108 of $108<.05$ \\
\hline LG.B $>0$ & 66 of $108<.05$ \\
\hline LG.D $>0$ & 10 of $108<.05$ \\
\hline
\end{tabular}

Note: Boldface indicates that the $P$ value matches the expectations of the model. Models with any $P$ values not matching expectation are not supported. Model 3 , in which landscape resistance is the dominant effect, is the only model that is supported by all expectations. $\mathrm{B}=$ barrier, $\mathrm{G}=$ genetics, $\mathrm{D}=$ distance, $\mathrm{L}=$ landscape. The period in the expectation abbreviations separates the covariate matrix from the two primary matrices. For example, BG.D indicates a Mantel test between the barrier and genetic matrices, with the distance matrix partialed out. NS $=$ not significant. 
Table 5: Significantly supported landscape models

\begin{tabular}{lc}
\hline Model & Monte \\
\hline FHEMRHSN |D & $P$ value \\
FHEMRNSN | D & .011 \\
FHEMRLSN | D & .017 \\
FLEMRLSN | D & .018 \\
FLEMRHSN | D & .022 \\
FNEMRLSN | D & .031 \\
FHENENSN | D & .037 \\
FNEMRHSN |D & .039 \\
FNEMRNSN | D & .039 \\
FLENRNSN | D & .042 \\
\hline
\end{tabular}

Note: Abbreviations for models consist of combinations of factor and level for factors forest $(\mathrm{F})$, elevation $(\mathrm{E})$, roads $(\mathrm{R})$, and slope (S) at levels high (H), middle (M), low (L), and none $(\mathrm{N}) ; \mid \mathrm{D}$ indicates that the distance matrix has been partialed out. For example, FHEMRNSN $\mid \mathrm{D}$ indicates high relationship to forest cover, minimum resistance at middle elevation, no relationship to roads, and no relationship to slope.

els, we were able to determine whether a black bear population in northern Idaho is primarily structured by the Kootenai River barrier, distance, or landscape-resistance gradients. The results indicate that isolation-by-barrier and isolation-by-distance models are poorly supported in comparison to that of isolation by landscape-resistance gradients. Evaluating multiple competing hypotheses identified land cover and elevation as the dominant factors associated with genetic structure. The unimodal pattern of increasing significance within a corner of the fourdimensional factorial provides strong support for the conclusion that high forest cover and middle elevations promoted gene flow and that topographical slope had no effect. Gene flow in this black bear population appears to be facilitated by forest cover at middle elevations, inhibited by nonforest land cover, and not influenced by topographical slope. Because of the equivocal support for the three levels of road resistance, we cannot determine the nature of road effects on gene flow in this population.

Movements indicated by genetic patterns represent a subset of all movements. Except for the most recent movements, only movements that led to breeding are documented. Nevertheless, our most supported models closely conform to the known habitat use patterns of black bears. Specifically, black bears in the eastern Cascade Mountains selected midelevation forest types while avoiding extensive bare areas and low-elevation forests (Lyons et al. 2003). In North Carolina, bear use was positively related to slope and low-mid-elevation forests, while they avoided high ridge tops (Powell and Mitchell 1998). Gaines et al. (2005), studying bears in the western Cascades, found strong negative associations with roads; our models were equivocal. However, the study area of Gaines et al. (2005) included major roads, such as Interstate 90 , that are not present in our study area.

Understanding the ultimate causes of the observed patterns of genetic structure in the population will depend on directly linking the behavior and movement of individuals to population-level patterns of gene flow. In addition, such movement studies could provide empirically estimated resistances associated with different landscape variables. In our study we attempted to bracket a range of possible relationships between landscape structure and gene flow by specifying multiple levels of each factor. It would be preferable to obtain empirical estimates from observed patterns of movement; however, no such data was available for bears in our study area.

This analysis differed from traditional population genetics approaches in two important ways: first, by calculating pairwise genetic distance between individuals rather than between groups, and second, by evaluating multiple competing organizational models to infer causation. Most commonly, population structure has been assessed using $F_{\mathrm{ST}}, G_{\mathrm{ST}}$, or assignment tests to measure structure between populations on either side of a putative barrier (e.g., Krings et al. 1999; Castella et al. 2000; Burton et al. 2002; Manel et al. 2005; Riley et al. 2006; but see Dupanloup et al. 2002; Manel et al. 2003). When we examined our data set using these methods, we obtained equivocal results. The parameter $G_{\mathrm{ST}}^{\prime}$, a standardized form of $G_{\mathrm{ST}}$ that is scaled by the maximum level possible given the observed amount of genetic variation (Hedrick 2005), is 0.097 between the Selkirk and Purcell Mountains. An assignment test correctly assigned $74 \%$ (54/73) of bears sampled in the Purcell Mountains and 89\% (65/73) of bears sampled in the Selkirk Mountains (Schwartz et al. 2006). Thus, based on traditional approaches, we would conclude that bears in northern Idaho are neither panmictic nor fully substructured by the agricultural valley separating these demes. While these results are consistent with our more general results, they are less informative concerning those factors that influence black bear movement and population substructuring.

Of the 110 tested hypotheses of landscape resistance to gene flow, two were similar to hypotheses tested in most past landscape genetics studies: panmictic populations separated by a putative barrier and isolation by distance. The major contribution of this study is the formal comparison of the amount of support for these hypotheses in competition with a factorial of potential relationships with four major attributes of landscape structure. Evaluation of the seven organizational models indicated that genetic differentiation in this population is primarily related to landscape-resistance gradients, with no independent distance or barrier effects. Thus, both the distance and barrier models are likely to be correlations with, and not causes 


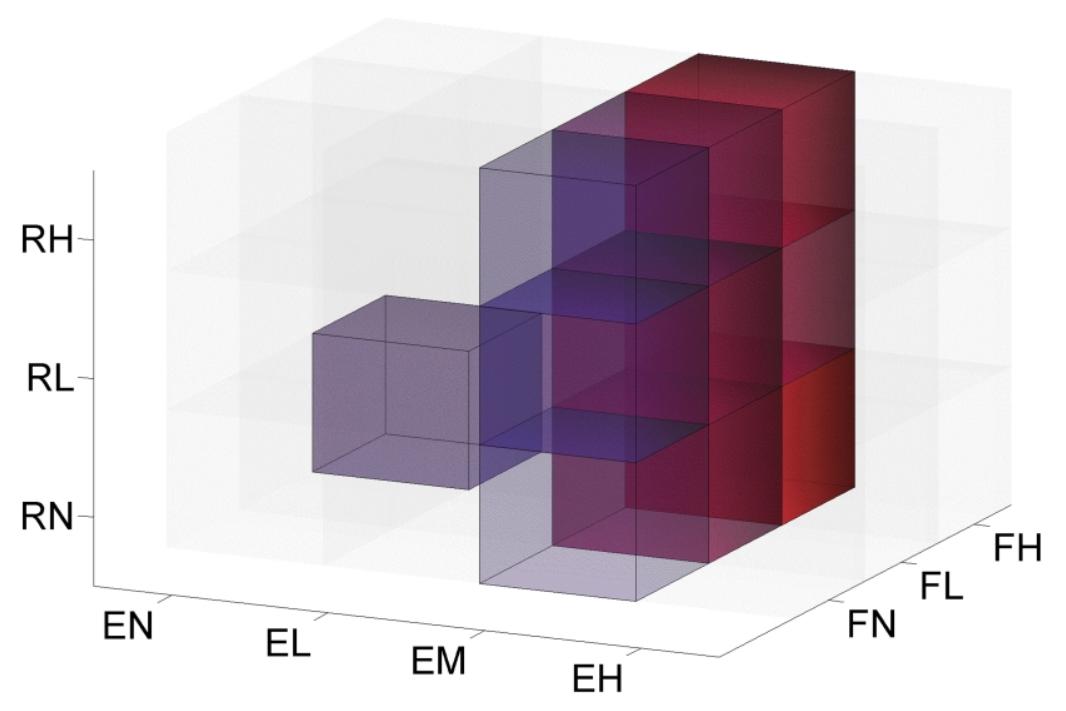

Figure 5: Visualization of the 10 landscape-resistance hypotheses that remain statistically significant $(P<.05)$ after the effects of geographical distance are partialed out. The space is a factorial of three landscape factors: roads, elevation, and land cover (for abbreviations, see table 1). All significant partial landscape models can be plotted in this subspace because the fourth factor, slope, had no relationship with genetic distance. The cubes each represent one of the 10 significant landscape-resistance models. The cubes are colored in a gradient from blue to red, with red being the most supported models based on the Monte Carlo significance of the partial Mantel test. The $P$ values corresponding to each cube are found in table 5 . The significant models are all clustered in a small subregion of the four-dimensional factorial space, with highest support for the models corresponding to strong relationships to forest cover and middle elevation, with equivocal support for the different levels of the roads factor and no relationship with slope.

of, the observed genetic pattern. As figure $6 C$ shows, the Kootenai River valley is the largest area of high resistance in this landscape and functionally may be a partial barrier. But this is not because it is a special structure in an otherwise permeable landscape. It emerges as a barrier because it contains large contiguous areas of landscape features associated with high resistance to gene flow.

One negative consequence of using grouping methods for population genetics is that assumptions of homogeneity within groups, if false, lead to large within-group variance, obscuring between-group differences. The reason that the barrier model performed relatively poorly was not because a barrier was assumed when none existed. It performed poorly because the panmictic assumptions on either side of the barrier were incorrect. Thus, in many cases it may be more parsimonious and informative to represent landscape resistance and its relationships with population structure as a gradient phenomenon rather than a categorical, patch-based entity. Representing the population structure in this way preserves internal information that would otherwise be lost about how genetic characteristics vary across space. Also, by representing population structure as a gradient phenomenon, it is possible to compare population gradients with landscape-resistance gradients, allowing rigorous evaluation of relationships between specific environmental features and population connectivity over large geographic extents. For the specific purpose of determining landscape connectivity and corridors, it is not enough to know that genetic structure exists. We need to know what landscape factors contributed to that structure.

Several authors have tested one or a few landscaperesistance models against global panmixia, barriers, or isolation by distance (e.g., Andreassen et al. 1998; Danielson and Hubbard 2000; Coulon et al. 2004, 2006). Our work extends these concepts by providing a comprehensive, factorial, multimodel approach in order to evaluate alternative hypotheses and identify the combination of environmental factors that appear to drive landscape-level patterns of gene flow.

\section{Scope and Limitations}

Genetic structure can have a substantial time lag in its response to changes in gene flow. This lag is related to effective population size $\left(N_{\mathrm{e}}\right)$ and substructure (Wright 1943; Nei and Chakravarti 1977; Waples 1998). For instance, using a basic equation of Wright (1943) that relates $F_{\mathrm{ST}}$, divergence time from a common ancestor $(t)$, and $N_{\mathrm{e}}$ $\left(F_{\mathrm{ST}(t)}=1-e^{-t / 2 N_{e}}\right)$, it can easily be shown that reaching $F_{\mathrm{ST}}=0.1$ takes between two and 21 generations as $N_{\mathrm{e}}$ changes from 10 to 100 . Given the difficulty in assessing $N_{e}$ in our open study area, however, we can give only 

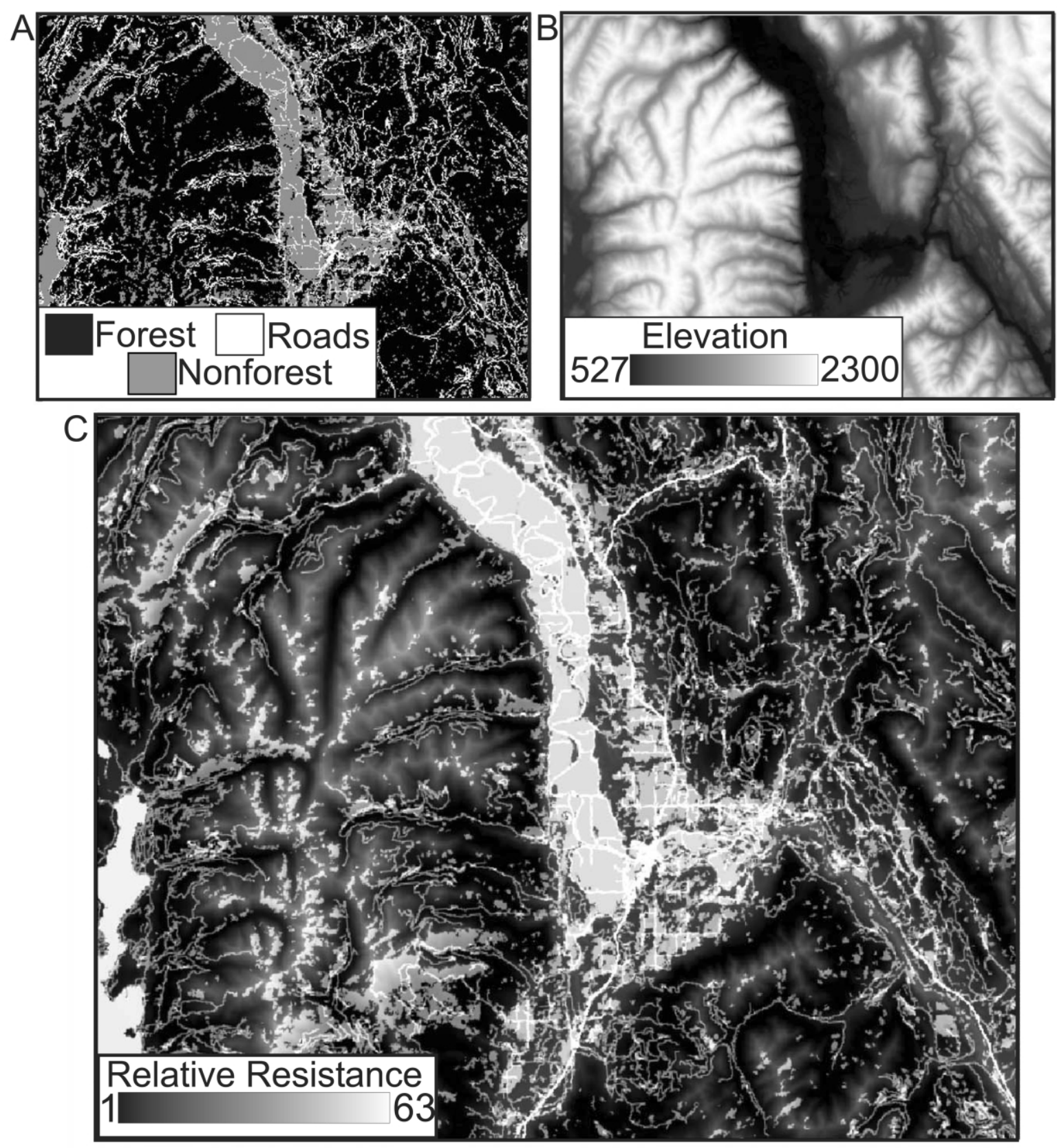

Figure 6: $A$, Simplification of the land cover map used in the analysis. $B$, Digital elevation model of the study area. $C$, Visualization of the most supported model (FHEMRHSN|D; table 5) of landscape resistance. This model predicts that gene flow in this study area is strongly related to land cover, with movement facilitated by forest cover and inhibited by nonforest cover types; that resistance to gene flow is lowest at middle elevations and increases at both low and high elevations; that gene flow is reduced by roads; and that gene flow is unrelated to slope.

qualified statements on the effects of time lags. In our study, this time lag to equilibrium is a possible cause of the equivocal results obtained for the effects of roads on landscape resistance. Many of the roads in our study area were built in the past $20-40$ years, and virtually all roads were absent 100 years ago. The same concern can be raised for our land cover-resistance model. While the overall land cover has probably changed relatively little in the past 100 years, some cover classes in the land cover-resistance model, such as increased agricultural development in the Kootenai River valley, were more recent events. Thus, the Kootenai valley may now be a greater barrier than the 
genetics indicate (though we know from ongoing radio telemetry studies that bears still cross it; J. Hayden, unpublished data). In general, however, the factors included in these models - particularly slope, elevation, and coarse land cover-have changed very little over the past century or more. Thus, we believe our results are robust with respect to recent changes in the landscape.

Another potential issue is translocation of individuals. In our study area, local governments have translocated several dozen bears from across the study area to the northern Selkirk Mountains over the past several decades (W. Wakkinen, unpublished data). These translocations serve to mix populations and dampen the effects of landscape-resistance gradients on genetic differences. In our study, however, we observed highly significant patterns of genetic differentiation despite these translocations, suggesting that the relationships between landscape structure and gene flow are strong.

Our approach evaluates statistical support for multiple organizational models of factors influencing gene flow. These methods do not, however, optimize estimates or resistance parameters. While our analysis provides clear support for landscape-resistance gradients based on lanc' cover and elevation as the dominant drivers of gene flow, it does not provide optimal estimates of the landscap $\rightarrow$ characteristics that minimize resistance and hence represent the best potential corridors. Further work in model optimization (see Dupanloup et al. 2002 for an example using genetic data) to estimate parameter values will be needed to determine the particular resistance parameter: associated with each landscape variable.

\section{Conclusion}

In northern Idaho, genetic structure in the black bear population is related to landscape gradients of land cover and elevation. The bear population in this study area is not divided into two panmictic subpopulations within th Selkirk and Purcell mountain ranges, separated by the Kootenai River valley, nor is its genetic structure best described by isolation by distance. Gene flow in this black bear population varies along gradients of landscape resistance related to elevation and forest cover.

By evaluating a full factorial of 110 resistance hypoth. eses, we were able to identify and map the strongest measured relationship between black bear genetic structure and landscape patterns. Such empirically based fine-scale maps of landscape resistance are needed by scientists, managers, and conservationists to facilitate evaluation of the potential effects of habitat fragmentation and of altered management and disturbance regimes on population connectivity. Finally, as more of the western landscape is being developed, there have been increasing numbers of efforts to protect corridors that facilitate movement of organisms. Using a multimodel landscape-resistance approach tested with genetic data can help robustly delineate potential corridors designed for specific species.

\section{Acknowledgments}

Funding for this work was provided by the Joint Fire Science Program, the U.S. Forest Service Northern Region, the U.S. Forest Service Rocky Mountain Research Station, and the Idaho Department of Fish and Game. We thank F. Allendorf, C. Flather, and R. King for their helpful comments and suggestions on an earlier version of this manuscript. We thank K. Pilgrim for her help with the laboratory work and database management.

\section{Literature Cited}

$\rightarrow$ Andreassen, H. P., K. Hertzberg, and R. A. Ims. 1998. Space-use responses to habitat fragmentation and connectivity in the root vole Microtus oeconomus. Ecology 79:1223-1235.

$\rightarrow$ Bowne, D. R., and M. A. Bowers. 2004. Interpatch movements in spatially structured populations: a literature review. Landscape Ecology 19:1-20.

Brody, A. J., and M. R. Pelton. 1989. Effects of roads on black bear movements in North Carolina. Wildlife Society Bulletin 17:5-10.

Burton, C., C. J. Krebs, and E. B. Taylor. 2002. Population genetic structure of the cyclic snowshoe hare (Lepus americanus) in southwestern Yukon, Canada. Molecular Ecology 11:1689-1701.

$\rightarrow$ Carr, L. W., and L. Fahrig. 2001. Effect of road traffic on two amphibian species of different vagility. Conservation Biology 15:10711078 .

Castella, V., M. Ruedi, L. Excoffier, C. Ibanez, R. Arlettaz, and J. Hausser. 2000. Is the Gibraltar Strait a barrier to gene flow for the bat Myotis myotis (Chiroptera: Vespertillionidae)? Molecular Ecology 9:1761-1772.

$\rightarrow$ Coulon, A., J. F. Cosson, J. M. Angibault, B. Cargnelutti, M. Galan, N. Morellet, E. Petit, S. Aulagnier, and A. J. M. Hewison. 2004. Landscape connectivity influences gene flow in a roe deer population inhabiting a fragmented landscape: an individual-based approach. Molecular Ecology 13:2841-2850.

Coulon, A., G. Guillot, J. F. Cosson, J. M. A. Angibault, S. Aulagnier, B. Cargnelutti, M. Galan, and A. J. M. Hewison. 2006. Genetic structure is influenced by landscape features: empirical evidence from a roe deer population. Molecular Ecology 15:1669-1679.

$\rightarrow$ Cushman, S. A. 2006. Effects of habitat loss and fragmentation on amphibians: a review and prospectus. Biological Conservation 128: 231-240.

Danielson, B. J., and M. W. Hubbard. 2000. The influence of corridors on the movement behavior of Peromyscus polionotus in experimental landscapes. Landscape Ecology 15:323-331.

deMaynadier, P. G., and M. L. Hunter Jr. 2000. Road effects on amphibian movements in a forested landscape. Natural Areas Journal 20:56-65.

Dupanloup, I., S. Schneider, and L. Excoffier. 2002. A simulated annealing approach to define the genetic structure of populations. Molecular Ecology 11:2571-2581.

ESRI. 2003. ArcGIS. Environmental Systems Research Incorporated, Redlands, CA. 
$\rightarrow$ Evanno, G., S. Regnaut, and J. Goudet. 2005. Detecting the number of clusters of individuals using the software STRUCTURE: a simulation study. Molecular Ecology 14:2611-2620.

Evett, I. W., and B. S. Weir. 1998. Interpreting DNA evidence. Sinauer, Sunderland, MA.

$\rightarrow$ Fahrig, L., J. H. Pedlar, S. E. Pope, P. D. Taylor, and J. F. Wegner. 1995. Effect of road traffic on amphibian density. Biological Conservation 73:177-182.

$\rightarrow$ Forbes, S. H., and J. T. Hogg. 1999 Assessing population structure at high levels of differentiation: microsatellite comparisons of bighorn sheep and large carnivores. Animal Conservation 2:223-233.

Frankham, R., J. D. Ballou, and D. A. Briscoe. 2002. Introduction to conservation genetics. Cambridge University Press, Cambridge.

$\rightarrow$ Gaines, W. L., A. L. Lyons, J. F. Lehmkuhl, and K. J. Raedeke. 2005. Landscape evaluation of female black bear habitat effectivenes and capability in the north Cascades, Washington. Biological Conservation 125:411-425.

$\rightarrow$ Gibbs, J. P. 1998. Amphibian movements in response to forest edges $\rightarrow$ roads, and streambeds in southern New England. Journal of Wildlife Management 62:584-589.

$\rightarrow$ Gompper, M. E., J. L. Gittleman, and R. K. Wayne. 1998. Dispersal $\rightarrow$ philopatry, and genetic relatedness in a social carnivore: comparing males and females. Molecular Ecology 7:157-163.

$\rightarrow$ Hedrick, P. W. 2005. A standardized genetic differentiation measure. Evolution 59:1633-1638.

$\rightarrow$ Kohn, M. H., E. C. York, D. A. Kamradt, G. Haught, R. M. Sauvajot $\rightarrow$ and R. K. Wayne. 1999. Estimating population size by genotyping faeces. Proceedings of the Royal Society B: Biological Sciences 266: 657-663.

$\rightarrow$ Krings, M., H. Geisert, R. W. Schmitz, H. Krainitzki, and S. Pääbo $\rightarrow$ 1999. DNA sequence of the mitochondrial hypervariable region II from the Neandertal type specimen. Proceedings of the National Academy of Sciences of the USA 96:5581-5585.

$\rightarrow$ Lande, R. 1988. Genetics and demography in biological conservation Science 241:1455-1460.

$\rightarrow$ Legendre, P. 1993. Spatial autocorrelation: trouble or new paradigm $\rightarrow$ Ecology 74:1659-1673.

Legendre, P., and L. Legendre. 1998. Numerical ecology. 2nd English ed. Elsevier, Amsterdam.

$\rightarrow$ Legendre, P., and M. Troussellier. 1988. Aquatic heterotrophic bacteria: modeling in the presence of spatial autocorrelation. Limnology and Oceanography 33:1055-1067.

Legendre, P., and A. Vaudor. 1991. The R package: multidimensional analysis, spatial analysis. Université de Montréal.

$\rightarrow$ Lyons, A. L., W. L. Gaines, and C. Servheen. 2003. Black bear resourc selection in the northeast Cascades, Washington. Biological Conservation 113:55- 62 .

$\rightarrow$ Manel, S., M. K. Schwartz, G. Luikart, and P. Taberlet. 2003. Landscape genetics: combining landscape ecology and population genetics. Trends in Ecology \& Evolution 18:189-197.

$\rightarrow$ Manel, S., O. E. Gaggiotti, and R. S. Waples. 2005. Assignment methods: matching biological questions with appropriate techniques. Trends in Ecology \& Evolution 20:136-142.

$\rightarrow$ Manning, A. D., B. Lindenmayer, and H. A. Nix. 2004. Continua and umwelt: novel perspectives on viewing landscapes. Oikos 104: 621-628.

Mantel, N. 1967. The detection of disease clustering and a generalizer $\rightarrow$ regression approach. Cancer Research 27:209-220.

McGarigal, K., and S. A. Cushman. 2005. The gradient concept of landscape structure. Pages 112-119 in J. Wiens and M. Moss, eds.
Issues and perspectives in landscape ecology. Cambridge University Press, Cambridge.

McIntyre, S., and G. W. Barrett. 1992. Habitat variegation, an alternative to fragmentation. Conservation Biology 4:197-202.

$\rightarrow$ Michell, M. S., and R. A. Powell. 2003. Response of black bears to forest management in the southern Appalachian Mountains. Journal of Wildlife Management 67:692-705.

$\rightarrow$ Mills, L. S., and F. W. Allendorf. 1996. The one-migrant-pergeneration rule in conservation and management. Conservation Biology 10:1509-1518.

Morgan, T. A., C. E. Keegan III, T. P. Spoelma, T. Dillon, A. L. Hearst, F. G. Wagner, and L. T. DeBlander. 2004. Idaho's forest products industry: a descriptive analysis. Resource Bulletin RMRS-RB-4. USDA Forest Service, Fort Collins, CO.

Mowat, G., and C. Strobeck. 2000. Estimating population size of grizzly bears using hair capture, DNA profiling, and mark-recapture analysis. Journal of Wildlife Management 64:183-193.

Nei, M., and A. Chakravarti. 1977. Drift variances of Fst and Gst statistics obtained from a finite number of isolated populations. Theoretical Population Biology 11:307-325.

Powell, R. A., and M. S. Mitchell. 1998. Topographical constraints and home range quality. Ecography 21:337-341.

Pritchard, J. K., P. Stephens, and P. Donnelly. 2000. Inference of population genetic structure using multilocus genotype data. Genetics 155:945-959.

Proctor, M. F., B. N. McLellan, C. Strobeck, and R. M. R. Barclay. 2005. Genetic analysis reveals demographic fragmentation of grizzly bears yielding vulnerability by small populations. Proceedings of the Royal Society B: Biological Sciences 272:2409-2416.

Riley, S. P. D., J. P. Pollinger, R. M. Sauvajot, E. C. York, C. Bromley, T. K. Fuller, and R. K. Wayne. 2006. A southern California freeway is a physical and social barrier to gene flow in carnivores. Molecular Ecology 15:1733-1741.

Rousset, F., 2000. Genetic differentiation between individuals. Journal of Evolutionary Biology 13:58-62.

Saccheri, I. J., R. A. Nichols, and P. M. Brakefield. 2001. Effects of bottlenecks on quantitative genetic variation in the butterfly $B i$ cyclus anynana. Genetical Research 77:167-181.

$\rightarrow$ Schwartz, M. K., L. S. Mills, K. McKelvey, L. S. Ruggiero, and F. W. Allendorf. 2002. DNA reveals high dispersal synchronizing the population dynamics of lynx. Nature 415:520-522.

Schwartz, M. K., S. A. Cushman, K. S. McKelvey, J. Hayden, and C. Engkjer. 2006. Detecting genotyping errors and describing black bear movement in northern Idaho. Ursus (forthcoming).

Scribner, K. T., J. A. Blanchong, D. J. Bruggerman, B. K. Epperson, C. Lee, Y. Pan, R. I. Shorey, H. H. Prince, S. R. Winterstein, and D. R. Luukkonen. 2005. Geographical genetics: conceptual foundations and empirical applications of spatial genetic data in wildlife management. Journal of Wildlife Management 69:1434-1453.

$\rightarrow$ Smouse, P. E., J. C. Long, and R. R. Sokal. 1986. Multiple regression and correlation extensions of the Mantel test of matrix correspondence. Systematic Zoology 35:627-632.

$\rightarrow$ Spear, J. R., J. J. Walker, T. M. McCollom, and N. R. Pace. 2005. Hydrogen bioenergetics in the Yellowstone geothermal ecosystem. Proceedings of the National Academy of Sciences of the USA 102: 2555-2560.

Taberlet, P., J. J. Camarra, S. Griffin, E. Uhrès, O. Hanotte, L. P. Waits, C. Dubois-Paganon, T. Burke, and J. Bouvet. 1997. Noninvasive genetic tracking of the endangered Pyrenean brown bear population. Molecular Ecology 6:869-876. 
$\rightarrow$ Tallmon, D. A., G. Luikart, and R. S. Waples. 2004. The allurin! simplicity and complex reality of genetic rescue. Trends in Ecology \& Evolution 19:489-496.

$\rightarrow$ Van Horn, R. C., A. L. Engh, K. T. Scribner, S. M. Funk, and K. E Holekamp. 2004. Behavioral structuring of relatedness in the spotted hyena (Crocuta crocuta) suggests direct fitness benefits of clanlevel cooperation. Molecular Ecology 13:449-458.

$\rightarrow$ Vilà, C., A. K. Sundqvist, O. Flagstad, J. Seddon, S. Bjornerfeldt, I. Kojola, A. Casulli, H. Sand, P. Wabakken, and H. Ellegren. 2002 Rescue of a severely bottlenecked wolf (Canis lupus) population by a single immigrant. Proceedings of the Royal Society of London B 270:91-97.

Vitalis, R., and D. Couvet. 2001. Estimation of effective population size and migration rate from one- and two-locus identity measures. Genetics 157:911-925.

$\rightarrow$ Vos, C. C., A. G. Antonisse-De Jong, P. W. Goedhart, and M. J. M. Smulders. 2001. Genetic similarity as a measure for connectivity between fragmented populations of the moor frog (Rana arvalis). Heredity 86:598-608.
Waples, R. S. 1998. Separating the wheat from the chaff: patterns of genetic differentiation in high gene flow species. Journal of Heredity 89:438-450.

Wasser, P. M., and C. Strobeck. 1998. Genetic signatures of interpopulation dispersal. Trends in Ecology \& Evolution 13:43-44.

Wiens, J. A. 2001. The landscape context of dispersal. Pages 96-109 in J. Clobert, E. Danchin, A. A. Dhondt, and J. D. Nichols, eds. Dispersal. Oxford University Press, Oxford.

With, K. A., R. H. Gardner, and M. G. Turner. 1997. Landscape connectivity and population distributions in heterogeneous environments. Oikos 78:151-169.

$\rightarrow$ Woods, J. G., D. Patkau, D. Lewis, B. N. McLellan, M. Proctor, and C. Strobeck. 1999. Genetic tagging of free-ranging black and brown bears. Wildlife Society Bulletin 27:616-627.

$\rightarrow$ Wright, S. 1943. Isolation by distance. Genetics 28:114-138.

Associate Editor: Michael E. Helberg Editor: Jonathan B. Losos 